\title{
Behavioral disorders and their relationship to performance enhancers for autistic children
}

\author{
* Eman Ramadan Abdeen Mohammad \\ * Prof. Magdy Hassan Youssef \\ ****Prof. Dr. Hany Mahmoud Abu Bakr
}

\section{Introduction and problem research:}

Disability in general is one of the important issues facing societies, which may impede the process of development and development in society, as the civilization of nations and their advancement is represented in the extent of their interest in raising generations in its various groups, including children with special needs. As for neglecting this group, It exacerbates their problems, doubles their disability, and becomes burdensome on their families and society. Hence, indicative and therapeutic intervention is necessary in order for them to integrate into society to the maximum extent of their abilities.

Autism disability is one of the most difficult and severe disabilities in terms of its impact on the behavior of the individual who suffers from it and his ability to learn, socialize, train, or achieve even a slight degree of social independence or the ability to protect oneself .

( (Mustafa Sadiq, Saad Al-Khamisi, 2006: 1)

Autism disorder is one of the disabilities that require more care and attention, (the Autism Society of America defines autism) as a type of developmental disorder, which appears in the first three years of a child's life, and results from neurological disorders that affect brain functions And it appears in the form of problems in several aspects: such as social interaction, verbal and non-verbal communication, and play activities, and these children respond to things more than they respond to people, and these children are disturbed by any change that occurs in their environment

(Naif Al-Zari 2014: 30)

*PhD Researcher - Department of Physical Education Foundations - Faculty of Physical Education for Boys, Alexandria University. **Professor of Sports Psychology, Department of Physical Education Fundamentals - Faculty of Physical Education, Alexandria University ***Professor, Department of Physical Education Foundations - College of Physical Education for Boys - Alexandria University. 


\section{ueblh1qmyp}

Autism spectrum disorder is a category of groups with special needs that attention and care has started to be noticeably recently, due to the general developmental disability that children in this category suffer from that affects the multiple aspects of the child's development and leads to his withdrawal and closure on himself, and autism is considered One of the most difficult developmental disabilities for a child. (Nadia Abu Al-Saud, 2002: 3)

DSM-IV-TR (APA, 2000) defines autism spectrum disorder as a disorder that includes deficits in three main characteristics, namely, a qualitative decline in reciprocal interaction, a qualitative decline in communication, stereotypical repetitive behaviors, or repetitive interests and activities. (Nadia Al-Balawi, 2010: 8 )

The Fifth Statistical Diagnostic Manual of Mental Disorders (DSM-5) (APA, 2013) defines autism as a highly complex developmental disorder that manifests in insufficient social interaction, delays in the onset of communication and language, and the emergence of stereotypical and repetitive behaviors (APA, 2013), and this is consistent with Worley \& Matson's definition(2011) autism spectrum disorder as a neurodevelopmental disorder characterized by a lack of social interaction and communication, in addition to the presence of repetitive stereotypical behaviors and interests.

(American Psychiatric ,2013:5)

Autism disorder is characterized by many main characteristics and symptoms, Core symptoms and associated symptoms that appear in the first three years of a child's life. The main characteristics of this disorder include deficiencies in the social aspect, deficiencies in verbal and non-verbal communication, in addition to repetitive stereotypical behaviors, specific interests and restrictive activities. Among the symptoms associated with this disorder are cognitive and cognitive deficiencies. (Mamoun Jamil, 2010:28)

The researcher believes that performance enhancers can be used as a treatment strategy to reduce behavioral disorders.

Muhammad Othman (1988) indicates that behavioral strikes are one of the aspects that psychologists care most about. People think appropriate or abnormal and thus feel the psychological pain and misery due to the psychological and emotional conflicts they suffer, and the behavior disorder weakens the ability of the individual to make judgments in general and to establish healthy and healthy relationships. (Muhammad Najati, 1988: 12)

And Repetitive Stereotyped Behaviors are one of the primary diagnostic criteria, as ASDs show a preoccupation with restrictive repetitive 
stereotypical behaviors and interests, which requires intervention to modify these behaviors

(Ola Ibrahim, 2011: 31)

The behavioral disorders experienced by the self-inflicted child result in a set of unacceptable behavior patterns such as self-harm behavior, which poses a threat to his life and personal safety, and this self-harm behavior consists of a series of repeated responses and agitation that is difficult to control, such as hitting the head on hard objects such as walls or On the ground or furniture, slapping or pulling the face with a fist, pulling hair, biting or biting the hand, scratching body parts with nails, and eating unfit things.

(sahar rbye, 2009: 85)

Hence the importance of focusing on behavioral disorders in children with autism, which can be described as behaviors that they exhibit frequently and regularly in most cases, and these behaviors are usually called by different names such as: stereotypical behavior, repetitive behavior and self-excitation behavior, but the stereotypical behaviors appear. In many forms, some are related to the senses, some are related to the movement of the limbs (hands and feet), and some are related to the movement of the body, and some are not related to movements but to thinking or other rituals that are not related to them. (Hanaa Shehata, 2014: 8)

Among the diagnostic criteria for autism spectrum disorder is the repetition of restricted interests and stereotyped behaviors, and stereotypical repetitive behaviors are a difficult challenge for children with the autism spectrum themselves and their caregivers. As a result of discomfort resulting from the insistence on routine and monotony on the one hand, and the overlap of stereotypical repetitive behaviors with the ability of the child on the autism spectrum to learn new skills. (Umniah Ibrahim, Mustafa Al-Hudaibi,

(2013: 194

Despite the difficulty of therapeutic interventions for children with autism disorder, there are a number of treatment directions that are concerned with their care and rehabilitation. To reach the best possible situation for them according to their potential, and these treatment directions depend on a set of therapeutic theories, including: behavioral therapy, art therapy, music therapy, play therapy, language therapy, and sensory integration therapy. (Ibrahim Badr, 2004: 106)

Bosavac and Sherda, Sheridon \& Posavac, Posavac (2011) indicate that the use of behavioral therapeutic methods is one of the most successful methods used in helping children with attention deficit, as these methods increase their ability to focus their attention and control their associated behavioral problems in the classroom. Behavioral behavior is easy to control children's behavior, and this program is easy to apply by parents at home and teachers at school, and this method is distinguished from medical treatment by the absence of negative side effects on children, and it is also characterized by providing physical and symbolic reinforcers. 
(Manar Shlon, 2011: 85)

Attention in behavioral therapy for ADHD is focused on strengthening attention in these children, as a means of reducing inappropriate behavioral patterns or responses that are unrelated to the performance of the desired behavior.

(Abdulrahman Sulaiman, 2011: 76)

Positive reinforcement is usually used with behavioral therapy for these children, and it means rewarding the child after performing the correct behavior that he is trained on, and positive reinforcement may be either physical, such as rewarding the child with some money or a piece of candy, or morally, such as applauding the child and praising him with different expressions of thanks . (Ali Ahmad, Faika Badr 1999: 9).

Reinforcement is defined as a person's tendency to repeat a behavior that brings him positive results or rid him of exposure to negative consequences. This is a scientific fact that has been clarified by basic and applied scientific research. Opinions differ, however, about how reinforcement works and what forms of reinforcement are more effective than others.

(Jamal Al-Khatib, 2014: 55).

The researcher conducted a study to identify the most important behavioral disorders on autistic children who were integrated into the educational process, and through it, the following was found.

(Table 1)

The most common types of behavioral disorders among the research sample

\begin{tabular}{|c|c|c|}
\hline Number & The ferry & $\begin{array}{c}\text { Percentage } \\
\%\end{array}$ \\
\hline 1 & يهز جسمه أو أحد أعضائه بشكل متكرر & $57.14 \%$ \\
\hline 2 & يضرب علي الاشياء بيده أو أصابعه & $85.7 \%$ \\
\hline 3 & يدور بجسمه حول نفسه والأخرين & $57.14 \%$ \\
\hline 4 & يركض أو يمشي أو يقفز فجأة وبشكل متكرر & $57.14 \%$ \\
\hline 5 & لئشرياء يده أمام وجهه مع أو بدون امساكه & $57.14 \%$ \\
\hline 6 & بلصورة أو يمرر يده علي أسطح الأثياء & $57.14 \%$ \\
\hline 7 & للافوران أو يدور حول الاشياء الغير مخصصة & $85.7 \%$ \\
\hline 8 & يرفرف بيده مع أو بدون إمساكه للأشياء & $71.42 \%$ \\
\hline 9 & يصدر إشارات ليس لها هدف واضح & $71.42 \%$ \\
\hline
\end{tabular}

Table (1) shows the types of typical repetitive motor behavior of the research sample, where the percentage ranged from what percentage Between $(57.14 \%$ : 
$85.7 \%$ ), which indicates the high level of some typical behaviors among the research sample.

In view of the existence of patterns of non-adaptive behavior among autistic children, the most prominent of which are: Repetitive stereotypical behaviors, as well as many studies have not targeted these behaviors in an organized manner, which pose a challenge to teachers of autistic children in consuming a lot of time and effort in the training process to modify these behaviors, and so I returned Stereotypical behaviors are among the most prominent reasons behind the failure of autistic children to learn the skills necessary for daily life and gain basic experiences, and given the uselessness of some programs that work to develop and modify the different behavioral patterns of autistic children and because reinforcement is one of the most appropriate treatment methods that help reduce disorders Behavioral, according to the studies and results that have proven the effectiveness of reinforcement in reducing some behavioral disorders.

Hence the importance of research to demonstrate the role of performance enhancers in reducing behavioral disorders for autistic children.

\section{The importance and need for research :}

Theoretical importance: The importance of this research is the essential addition of special education literature and the strengthening of studies in the field of behavior modification .

Applied importance: This research sheds light on the most effective promotional methods in reducing the level of behavioral disorders, which contributes to building behavior modification programs and determining the best and shortest ways through which to control the undesirable behaviors of children with autism, as this study combines appropriate and proven programs and methods With the scientific evidence that emerged from male and female teachers practicing the teaching profession.

\section{research aims :}

\section{The current research aims to identify :}

1- Promoting methods most often used to reduce behavioral disorders for autistic children.

2- The relationship between performance enhancers and behavioral disorders for autistic children.

\section{Research questions :}

1- What are the reinforcement methods most used to reduce behavioral disorders for autistic children?

2-Is there a statistically significant relationship between performance enhancers and behavioral disorders for autistic children ?? 


\section{Research fieldS :}

Subject area: where the study is determined by the variables of the subject of the study and the approach that the current study followsDescriptive method.

Spatial field : The study was determined by the place of application and that of the Comprehensive Center for Social Rehabilitation for Autistic Children Nasr El Nuba Center.

Temporal field: The study period is determined during the 2020/2021 academic year.

The human field: a sample of autistic children in Aswan Governorate Some of the terms mentioned in the research :

\section{1- behavioral disorders :}

It is an abnormal behavioral manifestation that appears in the form of differentiated responses from a morphological point of view, except that it is It is similar in that it is non-functional, meaning it has no function to perform, a behavior common in autistic children ( Koegel, K, 1999 :119).

And defined by "Mohammad Othman" (1988), it is all disturbed behavior through which the individual realizes a defective perception and distorted and tries to conform to reality on the basis of this disordered behavior (Mohammad Najati, 1988: 2).

\section{2- Performance boosters:}

Procedural definition: that they are those positive reinforcement methods that work to control behavioral disorders during the class period and include:

Nutritional reinforcements: include all types of food and drink preferred by the student .

Physical reinforcements: Physical reinforcers include things that an individual likes (games, stories, colors, movies, pictures, the ball, stars, a certificate of appreciation, pens, a bicycle ... etc.)

Symbolic reinforcers: They are replaceable symbols, and they are also specific symbols (such as points, stars, coupons, etc.) that the individual gets when performing the desired acceptable behavior.

\section{3- Autism:}

Sri Rushdie (2008 AD), quoting Kanner (1943), knows that autism is a state of isolation, severe withdrawal, and the inability to communicate with and interact with others, and children with autism are described as having severe language disorders (Sri Rushdie, 2008: 218).

\section{First: the research plan:}

\section{Research plan and procedures}

\section{Research Methodology:}

The researchers used the descriptive approach, due to its relevance with the nature of the research . 


\section{research community:}

The research community is represented by the (45) forty-five children with autism spectrum disorder in Aswan Governorate for the 2020/2021 academic year .

\section{The research sample:}

The research sample was deliberately chosen from children with autism disorder of medium severity, who were integrated into the educational process at the Comprehensive Center for Social Rehabilitation in Nasr al-Nuba, and they numbered (7) children between the ages of (9-12 years), and the research sample was chosen in light of the following :

-He must have an autism disorder of moderate severity .

-To be included in the educational process .

The researcher also selected (8) children with autism disorder of moderate severity for the pilot study by (4) girls and (4) boys from the School of Intellectual Education in Nasr al-Nuba.

Table No. (2) shows the description of the study sample :

Table (2)

Description of the study sample in terms of some demographic characteristics

\begin{tabular}{c|c|c|c|c|}
\hline \hline Total community & \multicolumn{2}{|c|}{ The exploratory research sample } & \multicolumn{2}{|c|}{ Basic Research Sample } \\
\cline { 2 - 5 } & Females & Males & Females & Males \\
\hline \hline (45) & $(4)$ & $(4)$ & $(2)$ & (5) \\
\hline \hline Total participants & \multicolumn{2}{|c|}{ (8) Children } & \multicolumn{2}{|c|}{ (7) Children } \\
\hline \hline
\end{tabular}

Table (2) shows the description of the research sample, as the research population reached (45) children, and the exploratory sample used by the researcher was (8) children, and the size of the basic study sample was (7) children.

\section{Table No. (3) shows the homogeneity of the study sample :}

The researcher conducted homogeneity for the members of the research sample in order to ensure that the data on the sample individuals are moderately distributed in all the variables under consideration (age, IQ, degree of autism) that may affect the results of the research, and this is evident in Table (3). 
Table (3)

The arithmetic mean, median, standard deviation, and coefficients

Skewness of search variables $(n=7)$

\begin{tabular}{c|c|c|c|c|c}
\hline \hline \multirow{2}{*}{ number } & \multirow{2}{*}{ Variables } & \multirow{2}{*}{$\begin{array}{c}\text { measruing } \\
\text { unit }\end{array}$} & & \multicolumn{3}{|c}{$\begin{array}{c}\text { Statistical significance of } \\
\text { characterization }\end{array}$} \\
\cline { 4 - 6 } & & $\begin{array}{c}\text { Coefficient } \\
\text { of torsion }\end{array}$ & $\begin{array}{c}\text { standard } \\
\text { deviation }\end{array}$ & SMA \\
\hline \hline 1 & $\begin{array}{c}\text { Chronological } \\
\text { age }\end{array}$ & $\begin{array}{c}\text { Year / } \\
\text { month }\end{array}$ & -0.359 & 1.38 & 10.7 \\
\hline 2 & I.Q & Degree & $-1.722-$ & 3.48 & 65.14 \\
\hline 3 & $\begin{array}{c}\text { The degree of } \\
\text { autism }\end{array}$ & Degree & 0.620 & 1.51 & 15.57 \\
\hline \hline
\end{tabular}

Table (3) shows the following: The torsion coefficients of the research sample variables (age, IQ, degree of autism) ranged between (0.620 - -0.359), where the values were confined to (3), which indicates the moderation of the research sample in that Variables.

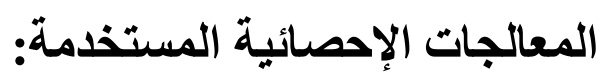

\section{Statistical processors used :}

According to the nature of the research and its objectives, the researcher used the following statistical treatment:

-percentage

- coefficient of torsion

- ETA Labs

-Standard deviation

$$
\text { - SMA }
$$

- T. Test for statistical difference

- coefficient (percentage change in averages - correlation coefficient

\section{Second: Data collection tools used in the research}

:The researchers used a set of tools and devices to collect research data, namely

\section{- Note :}

The researcher identified the research problem through scientific observation.

\section{- Expert opinion poll forms used in the study:}


The researcher designed and used the following forms :

A child with autism spectrum disorder data registration form: (name - age - autism rate - the child's language - parents and sibling data).

-A form for the list of reinforcers for a child with autism spectrum disorder

- Objective of the form:

Determine the type of reinforcer the child prefers to receive.

* Steps to prepare a list of reinforcers for a child with autism spectrum disorder:

- Access to scientific references and previous specialized studies .

- The form was presented in its initial form to the specialized experts .

-The form is shown to the parent or the school's inclusion specialist .

-personal interview:

The researcher conducted a personal interview with the experts, and each questionnaire was presented separately to express an opinion on each questionnaire separately for (10) experts with the aim of :

*Identifying the most important reinforcers for an autistic child .

Psychological measures used:

*The Autistic Child Scale (Adel Abdullah Muhammad, 2003)

*The Behavioral Disorders Scale (Mamoun Muhammad Jamil 2010 ).

Presentation, discussion and interpretation of results:

1-What are the reinforcement methods most used to reduce the behavioral disorders of autistic children ?

To answer this question, the researcher extracted the arithmetic mean and standard deviations of the respondents' responses to all the questionnaire items, then matched that with the judgment and evaluation table to determine the degree of appreciation and the rank of the item, and that was as follows :

\begin{tabular}{|c|c|c|c|c|c|}
\hline Phrase & Rank & SMA & $\begin{array}{l}\text { deviation } \\
\text { Standard }\end{array}$ & $\begin{array}{r}\text { The ratio } \\
\text { Percentile }\end{array}$ & $\begin{array}{c}\text { Degree } \\
\text { Appreciation }\end{array}$ \\
\hline Activity reinforcers & 3 & 2.11 & .79 & $\% 55.5$ & Medium \\
\hline Nutritional enhancers & 3 & 2.11 & .78 & $\% 55.5$ & Medium \\
\hline Physical reinforcers & 4 & 2.09 & .77 & $\% 54.5$ & Medium \\
\hline Symbolic reinforcers & 2 & 2.42 & .68 & $\% 71$ & big \\
\hline Social reinforcers & 1 & 2.73 & .53 & $\% 86.5$ & big \\
\hline \multicolumn{2}{|l|}{ الدرجة الكلية } & 2.29 & .71 & $\% 64.5$ & big \\
\hline
\end{tabular}


Given the above table and the criteria for judgment and evaluation, we note that the rates of use of reinforcers to reduce behavioral disorders for autistic children came in the following order, and social reinforcers were ranked first by a percentage average (2.73), the degree of appreciation (large), and the symbolic ,(\% 86.5) average (2.42), and a degree, ,\%71) reinforcers ranked second with a percentage of of appreciation (large), and in the third place nutritional and activity enhancers by (55.5\%), medium (2.11), and a rating (medium), and physical enhancers came in fourth place with a percentage of ( 54.5\%), a medium (2.09), and a (medium) grade . We note that the overall score falls in the range of a large estimate of (64.5\%), and a medium (2.29), which means that the result: Reinforcementary methods are used in reducing the behavioral disorders of autistic children to a large degree, respectively. (Social reinforcers, then symbolic reinforcements, then nutritional and activity reinforcements, and finally physical reinforcements )

The results of this study are consistent with the results of the study of Abdulaziz Mubarak Al-Shammari 2018.

\section{2- Is there a statistically significant relationship between performance enhancers and behavioral disorders for autistic children?}

\begin{tabular}{|c|l|l|l|l|l|l}
\hline \hline $\begin{array}{c}\text { Study } \\
\text { variables }\end{array}$ & $\begin{array}{l}\text { Behavioral } \\
\text { disorders }\end{array}$ & $\begin{array}{l}\text { Mental } \\
\text { category }\end{array}$ & $\begin{array}{l}\text { The } \\
\text { behavioral } \\
\text { category }\end{array}$ & $\begin{array}{l}\text { The } \\
\text { emotional } \\
\text { category }\end{array}$ & $\begin{array}{l}\text { Anatomical } \\
\text { category }\end{array}$ & $\begin{array}{l}\text { Developmental } \\
\text { category }\end{array}$ \\
\hline \hline $\begin{array}{c}\text { Performanc } \\
\text { e boosters }\end{array}$ & $* * 0.648$ & $* * 0.583$ & $* * 0.554$ & $* * 0.741$ & $* * 0.758$ & $* * 0.683$ \\
\hline $\begin{array}{c}\text { Activity } \\
\text { reinforcers }\end{array}$ & $* * 0.657$ & $* * 0.674$ & $* * 0.684$ & $* * 0.818$ & $* * 0.739$ & $* * 0.633$ \\
\hline $\begin{array}{c}\text { Nutritional } \\
\text { enhancers }\end{array}$ & $* * 0.536$ & $* * 0.683$ & $* * 0.671$ & $* * 0.487$ & $* * 0.758$ & $* * 0.675$ \\
\hline $\begin{array}{c}\text { Social } \\
\text { reinforcers }\end{array}$ & $* * 0.637$ & $* * 0.498$ & $* * 0.749$ & $* * 0.560$ & $* * 0.861$ & $* * 0.588$ \\
\hline $\begin{array}{c}\text { Symbolic } \\
\text { reinforcers }\end{array}$ & $* * 0.785$ & $* * 0.519$ & $* * 0.498$ & $* * 0.583$ & $* * 0.727$ & $* * 0.642$ \\
\hline $\begin{array}{c}\text { Physical } \\
\text { reinforcers }\end{array}$ & $* * 0.721$ & $* * 0.575$ & $* * 0.830$ & $* * 0.738$ & $* * 0.673$ & $* * 0.597$ \\
\hline \hline
\end{tabular}

** Correlation is Significant at the (0.01)

1- The existence of a positive correlation at the level of significance (0.01) between the total score of the behavioral disorders scale and the total score of performance enhancers, as the correlation coefficient between them reached (0.684).

2-The highest correlation coefficient between the mental group dimension and the nutritional enhancers approach as one of the performance enhancers dimensions was reached, where the correlation coefficient was $(0.683)$. 
3-The highest correlation coefficient between the behavioral category dimension and the material reinforcers method was reached as one of the performance enhancers dimensions, where the correlation coefficient reached (0.830).

4-The highest correlation coefficient between the emotional group dimension and the activity enhancers method was reached as one of the performance enhancers dimensions, where the correlation coefficient reached (0.818).

5-The highest correlation coefficient between the physical group dimension and the social reinforcers approach was reached as one of the performance enhancers dimensions, as the correlation coefficient reached $(0,861)$. It is the maximum correlation as one of the most important methods of performance enhancers according to the results of the study.

6-The highest correlation coefficient between the dimension of the developmental category and the method of nutritional enhancers as one of the dimensions of performance enhancers was reached, where the correlation coefficient reached (0.675).

Accordingly, we were able to verify the validity of the second hypothesis of the study, which confirms the existence of a correlation between behavioral disorders in its various categories represented in the mental, behavioral, emotional, physical, developmental category, and between the methods of performance enhancers represented in the activity, nutritional, social, symbolic enhancers. Materialism.

Based on these results, it becomes clear that the second hypothesis of the study has been achieved. The results of this study are in agreement with the study of Christina Desman et al. (2008), which concluded the importance of the cost of response and reinforcement in increasing the motivation of children in responding cessation, as well as showing the effect of the technique of reinforcement significantly, whether the reinforcement is material or moral enhancement in bringing about a noticeable change in their behavior .

\section{Conclusions and recommendations :}

The researchers deal with a presentation of the study's conclusions and recommendations, and what follows in detail :

\section{First: the conclusions}

Within the limits of the research problem and its importance, and in light of its objectives and assumptions and the nature of the sample, and within the framework of statistical treatments and the interpretation and discussion of the results, the researcher could reach the following conclusions : 
1- Reinforcement is considered a way to correct behavior in general. Based on the results obtained through this modest research, we have seen the importance of reinforcement of all kinds in evaluating and correcting the course of behavioral disorders in an autistic child .

2-Uses reinforcement methods to significantly reduce the behavioral disorders of autistic children, respectively. (Social reinforcers, then symbolic rein forcements, then nutritional and activity reinforcements, and finally physical reinforcements).

3- The existence of a positive correlation at the significance level (0.01) between behavioral disorders in its various dimensions and the dimensions of performance enhancers' methods.

\section{Second: Recommendations:}

\section{In light of the results of the study, the researcher recommends the following :}

1-Supporting educational bodies and institutions by providing scientific materials that include identifying the behavioral disorders of autistic children through educational references and seminars.

2-Paying attention to designing school curricula, activities and behavioral therapy programs on scientific grounds based on behavior modification theories. 3-Paying attention to establishing psychological clinics in school health centers in the various educational regions .

4-Paying attention to preparing psychologists to work in schools and hospitals to help children with emotional disorders, who are mentally different and those with autism who are able to learn to learn constructive coping methods and psychological compatibility, which will achieve more health for them .

5-The importance of using behavior modification techniques with autistic children with the support of normal children.

6- Recommending researchers to conduct more similar studies in different disciplines. 


\section{List of references}

First: Arabic references :

1)Ibrahim Mahmoud Badr (2004 AD) The Autistic Child "Diagnosis and

Treatment", Cairo: The Anglo-Egyptian Library .

2)Omniah Muhammad Ibrahim Abd al-Qadir, Mustafa Abdel-Mohsen al-Hudaibi (2013), the effectiveness of an instructional program in drawing in reducing the repetitive stereotypical behaviors of people with Asperger syndrome, C1, The Scientific Journal of the Faculty of Education in the New Valley, Assiut University, Egypt, p. 10, part one, 185-267.

3)Jamal Al-Khatib (2014) Human Behavior Modification, Amman: The University of Jordan .

4)Sahar Rabih Ahmad Abd Al-Muawjid (2009): The effectiveness of a program to develop some social skills and reduce self-harm behavior among autistic children, an unpublished master's thesis, College of Education, Ain Shams University .

5) Sri Rushdi Barakat (2008 AD) Psychological counseling for people with special needs, Riyadh, Dar Al Zahraa.

6) Abd al-Rahman Suleiman (2011): Attention deficit hyperactivity disorder in children. Cairo: Al-Jawhara Publishing House.

7) Abdulaziz Mubarak Muhammad Al-Shammari (2018): The reinforcement methods used by teachers of special education in reducing distracting and overactive behaviors in intellectual education programs, The Arab Journal for the Sciences of Disability and Giftedness, Issue (3), Hail, Saudi Arabia.

8) Ola Abdel-Baqi Ibrahim (2011 AD): Autism "autism" disorder, its symptoms - its causes and methods of treatment, along with training and treatment programs to develop the capacities of children with it, Cairo: The World of Books .

9) Ali Ahmad Al-Sayed, FaiKa Badr (1999). Attention disorder in children: causes, diagnosis, and treatment. Cairo: The Egyptian Renaissance Library . 
10) Mamoun Muhammad Jamil (2010), The Effect of Sports Activity in

Reducing the Typical Behavior of Autistic Child, PhD Thesis, Amman Arab University, Jordan.

11) Muhammad Othman Najati (1988): Psychology in our Daily Lives, 12th edition, Dar Al-Qalam .

12) Mustafa Ahmed Sadiq, Mr. Saad Al-Khamisi (2006 AD): The role of group play activities in developing communication among students with autism, Journal of the Faculty of Arts, Mansoura University - Egypt, Volume 1, Issue (39). 13)Manar Mahmoud Shloun (2011) The Effectiveness of a Behavioral Therapy Program Based on Positive Reinforcement in Reducing Attention Deficit among Kindergarten Children, an unpublished master's thesis, Amman University, Jordan .

14)Nadia Saleh Al-Balawi (2010) The Effectiveness of a Training Program Based on Technical Activities in Developing Social Interaction Skills and Reducing Stereotypical Behavior among Autistic Children in Jordan, PhD Thesis, Arab Amat University, Jordan .

15)Nadia Abdel Qader Abu Al-Saud (2002 AD): The effectiveness of a cognitivebehavioral treatment program in developing emotions and emotions among autistic people and their parents, Ph.D., Institute of Childhood Studies, Ain Shams University, Egypt .

16)Nayef bin Abdullah Al-Zarea (2014 AD) Introduction to Autism Disorder, "Basic Concepts and Methods of Intervention", 3rd Edition, Dar Al-Fikr Publishing House, Amman, Jordan .

17)Hanaa Shehata Ahmad (2014), the effectiveness of a program to improve joint attention in developing verbal communication skills for children with autism disorder, Master Thesis, College of Special Education, Ain Shams University

\section{Second: Foreign References:}

18- American Psychiatric Association (2013) Diagnostic and Statistical Manual of Mental Disorders: DSM-V, 5th ed. American Psychiatric Association Washington, DC: American Psychiatric Association.

19- Desman, chrisitiane; Franz, Petemanns \& petra, Hampela (2008). Deficit response inhibition in children with Attention Deficit Hyperactivity Disorder (ADHD): Impact of Motivation ? Child Neuropsychology , Volume 14, Issue 6 November 2008 , pages $483-503$

20- Koegel , K . (1999) Extended Reduction In Stereotypic Behavior, Of Students With Autism Through A self Management Treatment Package L Journal Of Applied Behavior Analysis, 23 , 


\title{
Behavioral disorders and their relationship to performance enhancers for autistic children
}

\author{
* Eman Ramadan Abdeen Mohammad \\ * Prof. Magdy Hassan Youssef \\ *** Prof. Dr. Hany Mahmoud Abu Bakr
}

The current research aims to identify the relationship between behavioral disorders and performance enhancers for autistic children by identifying the reinforcement methods most used to reduce behavioral disorders for autistic children, and the type of relationship between performance enhancers and behavioral disorders for autistic children .

The researcher used the descriptive approach, due to its relevance with the nature of the research. The basic study sample was deliberately chosen from children with moderate severity autism who were integrated into the educational process at the Comprehensive Social Rehabilitation Center in Nasr al-Nuba, and their number is (7) children aged between (9-12 years), The research sample was chosen in light of the following :

-He must have an autism disorder of moderate severity

-To be included in the educational process.

The results showed that reinforcement is a way to correct behavior in general. Based on the results obtained through this modest research, we have seen the importance of reinforcement of all kinds in evaluating and correcting the course of behavioral disorders in an autistic child. The results confirmed that reinforcement methods should be used to significantly reduce the behavioral disorders of autistic children, respectively. (Social reinforcers, then symbolic reinforcements, then nutritional and activity reinforcements, and finally physical reinforcements). It also resulted in a positive correlation and a positive correlation between behavioral disorders in its various dimensions and the dimensions of performance enhancers' methods in the study sample .

*PhD Researcher - Department of Physical Education Foundations - Faculty of Physical Education for Boys, Alexandria University. **Professor of Sports Psychology, Department of Physical Education Fundamentals - Faculty of Physical Education, Alexandria University ***:Professor, Department of Physical Education Foundations - College of Physical Education for Boys - Alexandria University. 